\title{
A PRELIMINARY STUDY TO INVESTIGATE THE RELATIONSHIP BETWEEN INDOOR ENVIRONMENT AND ITS EFFECT ON PHYSICAL AND MENTAL HEALTH
}

\author{
HIROKO NAKAOKA ${ }^{1}$, NORIMICHI SUZUKI ${ }^{1}$, YOSHITAKE NAKAYAMA ${ }^{1}$, KAZUNARI TAKAYA $^{1}$, \\ EMIKO TODAKA ${ }^{1}$, SHINJI TANAKA ${ }^{2}$, KAZUHIKO MATSUSHITA $^{2}$ \& CHISATO MORI ${ }^{1,3}$ \\ ${ }^{1}$ Centre for Preventive Medical Sciences, Chiba University, Japan \\ ${ }^{2}$ Sekisui House Ltd., Japan \\ ${ }^{3}$ Department of Bioenvironmental Medicine, Graduate School of Medicine, Chiba University, Japan
}

\begin{abstract}
The relationship between adverse health effects, including sensory irritation and decline in cognitive performance, and the exposure to indoor air pollutants has been considered inconclusive. This is possibly because the occurrence of relevant symptoms seems to largely depend on individual sensitivity and mental state. Therefore, further evaluation of the relationship between indoor environment and its related adverse health effects using subjective and objective data is required. In 2017, two new laboratory houses (LHs) were built on the campus of Chiba University (Japan) as part of a new project called the Chemiless Town Project, phase 3. This project aims to investigate the impact of the indoor environment on physical and mental health and to construct a healthy indoor environment. The interior and exterior appearances of the two LHs appear the same; however, the concentrations of chemicals inside them differ due to the differences in their construction and interior materials. The project commenced in November 2017 and will continue until 2021. In the project, approximately 400 participants will be recruited who will evaluate indoor air using sensory perception. The evaluation will be performed using objective methods, including monitoring brain waves and heart rate variability, and subjective methods, including completing self-reported questionnaires, while staying in each LH. Simultaneously, the indoor air samples of each laboratory will be collected and analysed. In 2017, 17 healthy female and 26 healthy male volunteers participated in the experiment. The median of sum concentrations of volatile organic compounds in the indoor air of each LH were 314 and $1674 \mu \mathrm{g} / \mathrm{m}^{3}$, respectively. No significant differences were found in terms of degrees of performance and relaxation of participants between the LHs. Additional research and analysis will be conducted with more participants to further examine the relationship between the indoor environment and related health effects.

Keywords: brain waves, Chemiless Town Project, healthy indoor environment, heart rate variability, indoor air quality, physical and mental health.
\end{abstract}

\section{INTRODUCTION}

Indoor air environment has a significant health impact on humans [1] as almost all individuals living in developed countries spend $>90 \%$ of their lives indoor [2]. While indoor air quality is known to be a key element for a healthy life, adverse health effects related to indoor air pollutants, including sensory irritation and decline in cognitive performance, have long been an inconclusive issue [3], [4]. In addition to adverse health effects, there are reports which state that allergic symptoms may relapse or worsen by chemical exposure in indoor air [5], [6]. The aetiology of sick building syndrome (SBS), which is a reaction to multiple chemicals at low-levels, seems to differ from that of the allergies that are reactions to specific antigenic agents. Nonetheless, improving indoor air quality to prevent the recurrence or exacerbation of allergy symptoms is a valid approach. There are also reports stating that the indoor environment affects human cognitive function [7], [8]. In contrast, the occurrence of symptoms or a health disorder from indoor air may largely depend on individual sensitivity and mental state [9], [10]. Therefore, further exploration of the relationship between the 
indoor environment and its adverse health effects using subjective and objective data is required.

The Centre for Preventive Medical Sciences at Chiba University (Chiba, Japan) initiated the Chemiless Town Project in 2017 to prevent the adverse health effects of indoor air pollution such as SBS [11]. This project is being conducted based on the concept of Environmental Preventive Medicine (EPM) which attempts to prevent diseases caused by pollutants in the environment by improving the overall environment [12], [13]. The Chemiless Town is a small model town on the university campus; some experiments were conducted here as test sites to practically apply EPM. Through this project, we have attempted to develop relevant evaluation methods for assessing indoor air quality from the approach of the sum of volatile organic compounds ( $\Sigma$ VOCs) and odour. As a result, we found that building materials, construction methods, furniture and housewares can principally contribute to the concentrations of chemicals in indoor air. We also found that if the concentration levels of $\Sigma$ VOCs and odour were sufficiently low, the number of individuals suffering from the symptoms significantly decreased [14].

In 2017, two laboratory houses (LHs) were newly built in the Chemiless Town to conduct a new study. In our previous study, we identified that the concentration level of $\Sigma$ VOCs was associated with the SBS symptoms [14]. In this study, we attempted to verify whether this concept is suitable for healthy people and susceptible adults and children, including those with histories of allergy symptoms. Approximately 400 volunteers will be recruited and requested to evaluate indoor air using their sensory perception. The evaluation will be performed using objective methods, including measuring brain waves and heart rate variability (HRV), and subjective methods, including completing self-reported questionnaires, while staying in each LH for approximately $90 \mathrm{~min}$. Additionally, during the monitoring of brain waves and HRV, the participants will perform some tasks. Simultaneously, the indoor air samples from each LH will be collected and analysed, and the indoor environment will be recorded. The preliminary study commenced in November 2017, and the project will continue until 2021.

The aim of this project was to investigate the impact of indoor environment on physical and mental health and to construct a healthy indoor environment considering this focus.

\section{MATERIALS AND METHODS}

\subsection{Experimental design}

A preliminary study of the project was conducted in 2017 from November 16 to December 22. It was designed to monitor brain waves and HRV of participants while they performed three tasks in a room of the LHs. Simultaneously, they were asked to complete self-reported questionnaires, including the Quick Environmental Exposure and Sensitivity Inventory (QEESI) questionnaire [15], [16]. The indoor air samples of each LH were collected and analysed each morning of all experimental days prior to the evaluation test. The evaluation tests were performed using objective methods, including monitoring brain waves and HRV as biological parameters, and subjective methods, including completing self-reported questionnaires.

The protocol of this study was approved under Approval No. 2737 by the Research Ethics Committee of the Graduate School of Medicine, School of Medicine, Chiba University. 


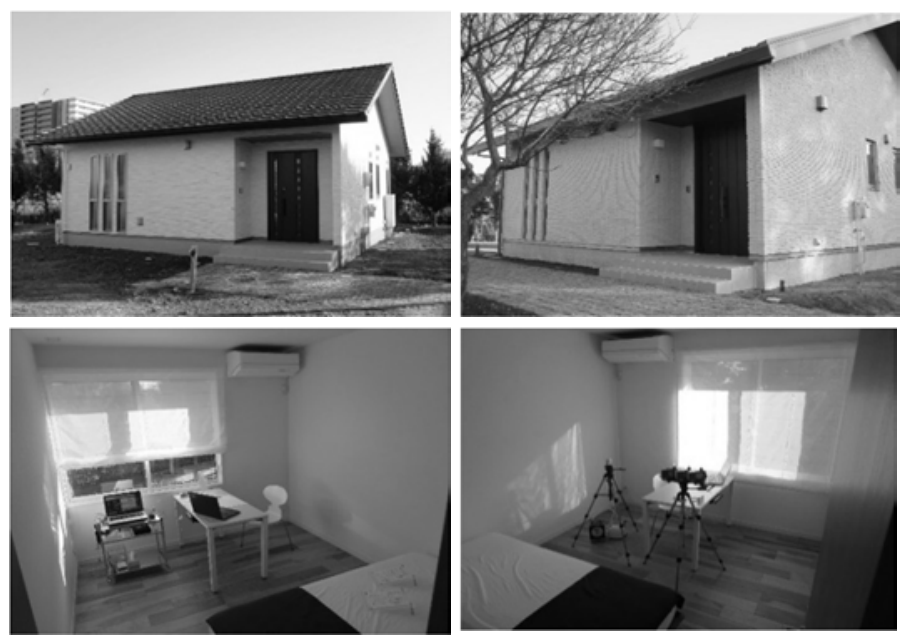

Figure 1: Experiments for this study are performed in the laboratory houses (LH). Upper left: LH-A (timber-framed structure); upper right: LH-B (light-gauge steel structure); bottom: bedrooms of each LH (left: LH-A, right: LH-B).

\subsection{Test sites}

In November 2017, two LHs were newly constructed in the Chemiless Town as part of a new project named the Chemiless Town Project, Phase 3 (Fig. 1). While the interior and exterior appearances of the two LHs, LH-A and LH-B, appear to be the same, the concentrations of chemicals inside differ due to different construction and interior materials. LH-A was constructed with a timber-framed structure, whereas LH-B was constructed with a lightgauge steel structure. There are two bedrooms and a living room in each $\mathrm{LH}$, and all bedrooms were used as test sites.

\subsection{Indoor air sampling and analysis}

The indoor air samples were collected in the morning by active sampling for $30 \mathrm{~min}$ in two bedrooms of each LH for all evaluation tests. Simultaneously, the environmental factors such as temperature and humidity were also recorded. In this study, 63 VOCs and 16 aldehydes were precisely analysed (Table 1). Before the air sampling was conducted, windows and doors were kept open for 30 min for ventilation; then they were closed for more than 2 hours. Next, air sampling was initiated. Facilitated ventilation systems in the rooms were operated during sampling. Measurement methods were performed in reference to 'The standard methods of air sampling and measurement' issued by the Ministry of Health, Labour and Welfare of Japan [17]. The air sampling was conducted with an active sampling method for 30 min using pumps, Shibata MP- $\Sigma 30 \mathrm{~N}$ and Shibata MP- $\Sigma 100 \mathrm{HN}$ (Shibata Scientific Technology Ltd. Saitama, Japan). As samplers, Tenax TA (Supelco, Sigma-Ardrich Co. LLC, MO, USA) was used to arrest the VOCs and a dinitrophenylhydrazine (DNPH) active gas tube for aldehyde (Shibata Scientific Technology Ltd. Saitama, Japan) was used to arrest the aldehydes. Air was passed through the Tenax TA and DNPH samplers at flow rates of 100 and $1000 \mathrm{~mL} / \mathrm{min}$, respectively. 
Table 1: Volatile organic compounds (VOCs) and aldehydes analysed in this study.

\begin{tabular}{|c|c|c|}
\hline & 63 VOCs & 16 aldehydes \\
\hline 2-Propanol & 2-Butoxyethanol & Formaldehyde \\
\hline Pentane & Nonane & Acetaldehyde \\
\hline Methyl acetate & Tricyclene & Acetone \\
\hline Dichloromethane & $\alpha$-Pinene & Acrolein \\
\hline 1-Propanol & 3-Ethyltoluene & Propanol \\
\hline Ethyl acetate & Camphene & 2-Butanone \\
\hline Hexane & 4-Ethyltoluene & Butanal \\
\hline Chloroform & 1,3,5-Trimethylbenzene & Benzaldehyde \\
\hline 1,2-Dichloroethane & 2-Ethyltoluene & Cyclohexanone \\
\hline 2,4-Dimethylpentane & $\beta$-Pinene & Pentanal \\
\hline $1,1,1$-Ttrichloroethane & $1,2,4$-Trimethylbenzen & Tolualdehyde \\
\hline Butanol & Octamethylcyclotetrasiloxane & Hexaldehyde \\
\hline Benzene & Decane & Heptanal \\
\hline Carbon tetrachloride & Isododecane & Octanal \\
\hline Cyclohexane & $p$-Dichlorobenzene & Nonanal \\
\hline 1,2-Dichloropropane & 2-Ethyl-1-hexanol & Decanal \\
\hline Bromodichloromethane & 3-Carene & \\
\hline Trichloroethylene & 1,2,3-Trimethylbenzene & \\
\hline 2,2,4-Trimethylpentane & p-Cymene & \\
\hline Heptane & Limonene & \\
\hline 4-Methyl-2-pentanone & 4-Ethyl-1,2-dimethylbenzene & \\
\hline Methylcyclohexane & Undecane & \\
\hline Toluene & 1,2,4,5-Tetramethylbenzene & \\
\hline Dibromochloromethane & decamethylcyclopentasiloxane & \\
\hline Butyl acetate & Dodecane & \\
\hline Octane & Tridecane & \\
\hline Tetrachloroethylene & Dodecamethylcyclohexasiloxane & \\
\hline Ethylbenzene & Texanol & \\
\hline$m, p$-Xylene & Tetradecane & \\
\hline Styrene & Pentadecane & \\
\hline \multirow[t]{2}{*}{$o$-Xylene } & Hexadecane & \\
\hline & $\begin{array}{l}\text { 2, 2, 4-Trimethyl-1, } \\
\text { 3-Pentanediol diisobutyrate }\end{array}$ & \\
\hline
\end{tabular}

The collected analytes of VOCs were extracted by thermal desorption and analysed by gas chromatography-mass spectrometry (GC-MS). The thermal desorption of the Tenax TA was conducted using a Turbo Matrix ATD650 (Perkin Elmer Inc., MA, USA). The analysis of VOCs was performed using an Agilent 5977A (GC7890B, MSD5977A) (Agilent Technologies Inc., CA, USA) in the SCAN mode (m/z, 40-350). Split ratio was 20:1, and transfer line temperature was $230^{\circ} \mathrm{C}$. A $30 \mathrm{~m} \times 0.25 \mathrm{~mm}$ column with a film thickness of 1.0 $\mu \mathrm{m}$ (Agilent J\&W DB-1) (Agilent Technologies Inc., CA, USA) was used as the GC analytical column. Helium (purity: $>99.999999 \%$ ) at a column flow rate of $1.0 \mathrm{~mL} \mathrm{~min}{ }^{-1}$ was used as the GC carrier gas. The GC oven temperature was maintained at $35^{\circ} \mathrm{C}$ for $5 \mathrm{~min}$ and then increased to $240^{\circ} \mathrm{C}$ at a rate of $10^{\circ} \mathrm{C} / \mathrm{min}$. The analysis of aldehydes was performed 
using a Prominence UFLC with two LC-20AD liquid supply pumps, a SIL-20AC auto sampler and a SPD M20A photodiode array detector (Shimadzu Co., Kyoto, Japan). As a column, a $150 \mathrm{~mm} \times 4.6 \mathrm{~mm}$ id Ascentis RP-Amide column with $2.7 \mu \mathrm{m}$ particle size (SigmaArdrich Co. LLC, MO, USA) was used. The flow rate was $1.0 \mathrm{~mL} / \mathrm{min}^{-1}$ and the mobile phase was a mixed solution of acetonitrile/water at 40/60 (solution A) and 80/20 (solution B). 30 minutes of $100 \%$ solution A was followed by 55 minutes of $25 \%$ solution B, after which solution B was increased to $100 \%$ and maintained for 5 minutes.

The limit of quantification for each of the chemicals was $1.0 \mu \mathrm{g} / \mathrm{m}^{3}$. In this study, $\Sigma$ VOCs was defined as the sum of the concentration levels of the compounds present in the chromatogram from n-hexane to n-hexadecane using the response factor of toluene, 2propanol, pentane, methyl acetate, 1-propanol, ethyl acetate, formaldehyde, acetaldehyde, acrolein, acetone and propanol, which were determined by their individual response factors.

\subsection{Evaluation by human sensory perception}

From November 16 to December 22 of 2017, 17 healthy female and 26 healthy male volunteers were recruited for a preliminary study to evaluate the indoor air quality of each LH using sensory perception.

Before the evaluation, the aims of the study and test procedures (Fig. 2) were explained to each participant and informed consent was obtained. The body temperatures, systolic/diastolic blood pressures and pulses of each participant were measured as a health check prior to the experiments in the anteroom. Chest nitric oxide levels were also measured using a Niox Vero (Chest M.I. Inc., Tokyo, Japan), which is a screening tool for asthma. The participants then entered the LH and remained there for approximately $90 \mathrm{~min}$. Almost all experiments were performed using four participants at once, each staying in one bedroom. In the test sites, the participants were seated before a personal computer (PC), and the sensor bands (two electrodes) for the measurement of brain waves were attached to their foreheads. An optical probe of a photoplethysmogram measuring device was then mounted on a fingertip of each participant's non-dominant hand. The brain waves were measured using a BrainPro FM-929 (Futek Electronics Co., Ltd. Yokohama, Japan), and the HRV was measured by a TAS9VIEW (YKC Corporation, Tokyo, Japan) for $30 \mathrm{~min}$. Electroencephalography is a medical imaging technique used to reflect brain state or activity [18]. HRV reflects the function of the autonomic nervous system (ANS) as heart rates are regulated by the ANS. Since the measurements of HRV can directly indicate the status of the ANS, it is used to evaluate the health impacts caused by various environmental factors [19]. While monitoring the brain waves and HRV for $30 \mathrm{~min}$, the participants performed three tasks as instructed by the narration of the PC, which included single-digit addition, N-back tasks, and a task involving deep breathing to relax. Additionally, the participants completed self-reported questionnaires on SBS symptoms, odour and the impression of the test site. QEESI was performed on the screen of the PC, and the participants relaxed on a chair or bed at the test sites. QEESI is a screening instrument for multiple chemical sensitivity [15], [16]. The criterion for the classification of sensitivity follows the study of Hojo et al. [20], [21]. In this study, 'QEESI (+) positive' means 'sensitive to chemicals' and 'QEESI (-) negative' means 'insensitive to chemicals'. The self-reported questionnaire investigated about the SBS symptoms and odour. The symptom query was scored from 1 to 4 (1: no symptoms; 2: minor symptoms; 3 : moderate symptoms and 4 : severe symptoms). The odour query was scored from 1 to 6 (1: odourless; 2: slight odour; 3: weak odour; 4: distinct odour; 5: strong odour and 6: poignant odour). The three tasks included 1-digit addition, the N-back task and relaxation. 


\begin{tabular}{|c|c|c|c|}
\hline $10: 30-11: 00$ & $12: 45-13: 15$ & $13: 20-13: 50$ & $13: 50-14: 50$ \\
\hline $\begin{array}{c}\text { of Indoor } \\
\text { Environment }\end{array}$ & $\begin{array}{c}\text { Explanation and } \\
\text { Health Check }\end{array}$ & $\begin{array}{l}\text { Monitoring } \\
\text { and Tasks }\end{array}$ & $\begin{array}{c}\text { Self-reported } \\
\text { questionnaire } \\
\text { and Relax }\end{array}$ \\
\hline $\begin{array}{l}\text { Airborne } \\
\text { volatile organic } \\
\text { compounds } \\
\text { Temperature } \\
\text { Relative } \\
\text { Humidity }\end{array}$ & $\begin{array}{l}\text { Informed consent } \\
\text { Body temperature } \\
\text { Blood pressure } \\
\text { Pulse } \\
\text { Nitric oxide levels } \\
\text { in bless }\end{array}$ & $\begin{array}{l}\text { Brain Waves } \\
\text { HRV } \\
\text { Single-digit } \\
\text { addition } \\
\text { N-back Task } \\
\text { Deep breath to } \\
\text { relax }\end{array}$ & $\begin{array}{l}\text { SBS symptoms } \\
\text { Odour } \\
\text { Impression of } \\
\text { test sites } \\
\text { QEESI }\end{array}$ \\
\hline Test site & Anteroom & Test site & Test site \\
\hline
\end{tabular}

Figure 2: Test procedure of the preliminary study.

\subsection{Data analysis}

The data from all participants were analysed. To determine the statistical differences between the objective parameters (i.e. brain waves and HRV) and the results of each task in the LHs, two-sided Mann-Whitney's $U$-test was used. The differences with $p<0.05$ were considered to be statistically significant. Spearman rank correlation was calculated to assess the correlation between $\Sigma$ VOCs and the above data.

\section{RESULTS}

\subsection{Participants and indoor environmental factors of each test site}

The characteristics of the participants and the measurement level of the indoor air quality of the test sites are shown in Table 2. Twenty-one people ( 8 females and 13 males) evaluated the indoor air quality of LH-A, and 22 people ( 9 females and 13 males) evaluated that of LHB. The median age of the participants was 23 years (range: 20-59 years), and most of the participants were university students. Fifteen people (35\%) were screened for 'sensitive to chemicals' using QEESI.

The indoor climate conditions, temperature and relative humidity inside the LHs were found to be similar; however, the concentration levels of $\Sigma$ VOCs in the indoor air of each LH were significantly different $(p<0.05)$.

\subsection{Objective parameters (brain waves and HRV) and task performance}

As an objective parameter of the degree of relaxation, the ' $\alpha$ frequency $/ \beta$ frequency' of brain waves and LF (low-frequency)/HF (high-frequency) ratios of HRV were calculated as parameters of relaxation (Table 3). No significant differences in the $\alpha / \beta$ and LF/HF ratios were observed between the LHs. Regarding the results of task performance, there were no significant differences between the LHs. In Table 3, the numbers of single-digit addition 
Table 2: Characteristics of participants and indoor environmental factors of the test sites.

\begin{tabular}{lll}
\hline & LH-A & LH-B \\
\hline Participants, $\mathrm{n}$ & 21 & 22 \\
Gender (female) & 8 & 9 \\
Age, years; median (range) & $23(20-59)$ & $24(20-59)$ \\
QEESI+ positive, n $(\%)$ & $8(38 \%)$ & $7(32 \%)$ \\
$\Sigma$ VOCs, $\mu \mathrm{g} / \mathrm{m}^{3} ;$ median $( \pm \mathrm{SD})$ & $1674( \pm 712)^{*}$ & $314( \pm 72)^{*}$ \\
Temperature, ${ }^{\circ} \mathrm{C} ;$ median $( \pm \mathrm{SD})$ & $23.5( \pm 3.7)$ & $22.8( \pm 3.5)$ \\
Relative humidity, $\%$; median $( \pm \mathrm{SD})$ & $35.5( \pm 12.4)$ & $37.7( \pm 13.5)$ \\
\hline
\end{tabular}

$* p<0.05$; SD, standard deviation; LH, laboratory house; QEESI, Quick Environmental Exposure and Sensitivity Inventory; $\Sigma$ VOCs, sum of volatile organic compounds.

Table 3: Results of brain waves, HRV and task performance.

\begin{tabular}{llc}
\hline & $\begin{array}{l}\text { LH-A } \\
\text { median }( \pm \mathrm{SD})\end{array}$ & $\begin{array}{c}\text { LH-B } \\
\text { median }( \pm \mathrm{SD})\end{array}$ \\
\hline Brain wave, $\alpha / \beta$ & $2.63( \pm 0.45)$ & $2.19( \pm 0.44)$ \\
HRV, LF/HF & $1.18( \pm 0.12)$ & $1.21( \pm 0.17)$ \\
Task 1: single-digit addition & $416( \pm 65.8)$ & $435( \pm 62.3)$ \\
Task 2: N-back & $100( \pm 2.74)$ & $100( \pm 7.56)$ \\
\hline $\begin{array}{l}\text { LH, laboratory house; HRV, heart } \\
\text { frequency. }\end{array}$ & rate variability; LF/ HF, low-frequency/high- \\
The numbers of Task 1 (single-digit addition), the scores achieved by the participants; \\
The numbers of Task 2 (N-back), the numbers of correct answers.
\end{tabular}

indicate the scores achieved by the participants and N-back task indicate the numbers of correct answers.

\subsection{Perceived air quality by participants in LH-A and LH-B}

Based on the result of the participants' subjective assessments of the indoor air quality, 9 (5 females and 4 males) of the 43 participants complained of the SBS symptoms during their stay in the LHs. The number of participants who claimed the presence of symptoms was 5 (3 females and 2 males) at LH-A and 4 (2 females and 2 males) at LH-B, respectively. The mean scores for the symptoms were 2.6 at LH-A and 2.3 at LH-B. There was no significant interaction in the occurrence of the SBS symptoms at LH-A and LH-B. All participants staying in LH-A could smell some kind of odour inside the room, and they indicated that the odour intensity in LH-A was significantly higher than that in LH-B $(p<0.01)$. The correlation coefficient between $\Sigma$ VOCs and the odour intensity score was $r=0.66$. However, there were no statistically significant evidences that the participants staying in the environment with lower airborne VOCs indicated high-performance or were more relaxed (Table 4). 
Table 4: Spearman's correlation coefficient by rank test between $\Sigma$ VOCs and the objective and subjective data of participants.

\begin{tabular}{ccccccc}
\hline & $\alpha / \beta$ & LF/HF & $\begin{array}{c}\text { Single-digit } \\
\text { addition }\end{array}$ & N-back & $\begin{array}{c}\text { SBS } \\
\text { symptoms }\end{array}$ & $\begin{array}{c}\text { Odour } \\
\text { intensity }\end{array}$ \\
\hline$\Sigma$ VOCs & 0.29 & 0.05 & -0.25 & 0.21 & 0.10 & $0.66^{*}$ \\
\hline $\begin{array}{l}* p<0.01 ; \mathrm{LF} / \mathrm{HF}, \text { low-frequency/high-frequency; } \\
\text { organic compounds; SBS, sick building syndrome. }\end{array}$
\end{tabular}

\section{DISCUSSION AND CONCLUSION}

In this preliminary study, 43 healthy participants evaluated the indoor air quality of 2 LHs by objective and subjective methods. The indoor environmental factors such as VOCs, temperature and relative humidity for all test sites used for evaluation were also measured. Practically, in this study, no significantly different effects were observed between the two LHs, of which the concentration levels of the airborne chemicals were different in terms of the objective data obtained by monitoring the brain waves, HRV and task performance and the subjective data, including the occurrence of SBS symptoms. However, the participants indicated that the odour intensity was comparatively stronger at LH-A, which had higher concentration levels of $\Sigma$ VOCs, than LH-B.

SBS is suspected to occur through the exposure to chemicals in indoor air; however, the onset of symptoms considerably varies for every individual. Indeed, it is considered that more susceptible and sensitive individuals tend to show SBS symptoms [22]. In our previous study, it was revealed that odour intensity was also significantly correlated with SBS symptoms, particularly among sensitive people [14]. Although there was a difference in the concentration levels of airborne VOCs between the two LHs and the participants could distinguish a difference in the odour intensity according to this difference, no significant effects were observed in this study. The possible reason is that almost all participants were young and healthy students and that the VOC levels were sufficiently low for the healthy people. In addition, some researchers consider the occurrence of SBS symptoms to be largely dependent on a person's mental state [9], [10]. The two LHs used as test sites in this study are smart and well-designed houses; thus, their appearance possibly had positive effects on the mind of young people.

As the next step of our project, we plan to further explore and analyse the indoor air quality using a greater variety of participants and larger number of variables such as ventilation frequency, noise, lighting and indoor greenery. Therefore, we will continue to examine the relationship between the indoor environment and its effects on physical and mental health to prevent the occurrence of SBS symptoms or the exacerbation of allergy symptoms. As an ultimate goal, we aim to construct a healthy indoor environment that will allow people to enjoy long and healthy lives.

\section{ACKNOWLEDGEMENT}

This study was supported by JSPS KAKENHI Grant Number 15K00613 and Sekisui House Ltd.

\section{REFERENCES}

[1] Sundell, J., On the history of indoor air quality and health. Indoor Air, 14(7), pp. 51$58,2004$. 
[2] Klepeis, N. E., Nelson, W.C., Ott, W.R., Robinson, J.P., Tsang, A.M., Switzer, P., Behar, J.V., Hern S.C. \& Engelmann W.H., The national human activity pattern survey (NHAPS): a resource for assessing exposure to environmental pollutants. Journal of Exposure Analysis and Environmental Epidemiology, 11, pp. 231-252, 2001.

[3] Lan, L., Wargocki, P., Wyon, D.P. \& Lian Z., Effects of thermal discomfort in an office on perceived air quality, SBS symptoms, physiological responses and human performance. Indoor Air, 21, pp. 376-390, 2011.

[4] Tham, K.W., Indoor air quality and its effects on humans - A review of challenges and developments in the last 30 years. Energy and Building, 130, pp. 637-650, 2016.

[5] Mendell, M.J., Indoor residential chemical emissions as risk factors for respiratory and allergic effects in children: a review. Indoor Air, 17, pp. 259-277, 2007.

[6] Fabian, M.P., Adamkiewicz, G., Stout, N.K., Sandel, M. \& Levy, J.I., A simulation model of building intervention impacts on indoor environmental quality, pediatric asthma, and costs. Journal of Allergy and Clinical Immunology, 133(1), pp. 77-84, 2014.

[7] Allen, J.G., MacNaughton, P., Satish, U., Santanam, S., Vallarino, J. \& Spengler, J.D., Association of cognitive function scores with carbon dioxide, ventilation, and volatile organic compound exposures in office workers: A controlled exposure study of green and conventional office environments. Environmental Health Perspectives, 124(6), pp. 805-812, 2016.

[8] MacNaughton, P., Satish, U., Laurent J.G.C., Flanigan, S., Vallarino, J., Coull B., Spengler, J.D. \& Allen, J.G., The impact of working in a green certified building on cognitive function and health. Building and Environment, 114, pp. 178-186, 2017.

[9] Labarge, A.S. \& McCaffre, R.J., Multiple chemical sensitivity: A review of the theoretical and research literature. Neuropsychology Review, 10, pp. 183-211, 2000.

[10] Mckeown-Eyssen, G.E., Baines, C.J., Marshall, L.M., Jazmaji, V. \& Sokoloff, E.R., Multiple chemical sensitivity: discriminant validity of case definitions. Archives Environmental Health, 56, pp. 406-412, 2001.

[11] Nakaoka, H., Todaka, E. \& Mori, C., Chemi-less town project to prevent sick building syndrome: from the view point of the environmental preventive medicine using sustainable health town by decreasing the use of chemicals. Proceedings of the $6^{\text {th }}$ International Conference on Indoor Air Quality, Ventilation and Energy Conservation in Buildings, pp. 541-547, 2007.

[12] Mori, C. \& Todaka, E., Establishment of sustainable health science for future generation: from a hundred years ago to a hundred years in the future. Environmental Health and Preventive Medicine, 14, pp. 1-6, 2009.

[13] Mori, C. \& Todaka, E., A new concept for protecting our children - Environmental Preventive Medicine. Environmental Contaminants and Children's Health, Maruzen Planet: Tokyo, pp. 99-115, 2011.

[14] Nakaoka, H., Todaka, E., Seto, H., Saito, E., Hanazato M., Watanabe, M. \& Mori, C., Correlating the symptoms of sick-building syndrome to indoor VOCs concentration levels and odour. Indoor Built Environment, 23, pp. 804-813, 2014.

[15] Miller, C.S. \& Prihoda, T.J., The environmental exposure and sensitivity inventory (EESI): a standardized approach for measuring chemical intolerance for research and clinical applications. Toxicology and Industrial Health, 15, pp. 370-385, 1999.

[16] Miller, C.S. \& Prihoda, T.J., A controlled comparison of symptoms and chemical intolerances reported by Gulf War veterans, implant recipients, and persons with multiple chemical sensitivity. Toxicology and Industrial Health, 15, pp. 386-397, 1999. 
[17] Notice of "The standard methods of air sampling and measurement" (in Japanese); Japanese Ministry of Health, Labour and Welfare: wwwl.mhlw.go.jp/houdou/ 1206/h0629-2_b_13.html. Accessed on: 15 Feb. 2018.

[18] Komori, T., Tamura, Y., Mitsui, M., Matsui, J., Uei, D. \& Aoki, S., A preliminary study to investigate relaxation and sleep-inducing effects of cedrol. The Open Access Journal of Science and Technology, 4, 2016. doi:10.11131/2016/101228.

[19] Mizukoshi, A., Kumagai, K., Yamamoto, N., Noguchi, M., Yoshiuchi, K., Kumano, H., Sakabe, K. \& Yanagisawa Y., In-situ real-time monitoring of volatile organic compound exposure and heart rate variability for patients with multiple chemical sensitivity. International Journal of Environmental Research and Public Health, 12, pp. 12446-12465, 2015.

[20] Hojo, S., Ishikawa, S., Kumano, H., Miyata, M. \& Sakabe, K., Clinical characteristics of physician-diagnosed patients with multiple chemical sensitivity in Japan. International Journal of Hygiene and Environment Health, 211, pp. 682-689, 2008.

[21] Hojo,S., Sakabe, K., Ihikawa, S., Miyata, M. \& Kumano, H., Evaluation of subjective symptoms of Japanese patients with multiple chemical sensitivity using QEESI ${ }^{\mathcal{O}}$ : Environmental Health Preventive Medicine, 14, pp. 267-275, 2009.

[22] Ferguson, A., Penney, R. \& Solo-Gabriele, H., A review of the field on children's exposure to environmental contaminants: A risk assessment approach. International Journal of Environmental Research and Public Health, 14, p. 265, 2017. doi: 10.3390/ijerph14030265. 